
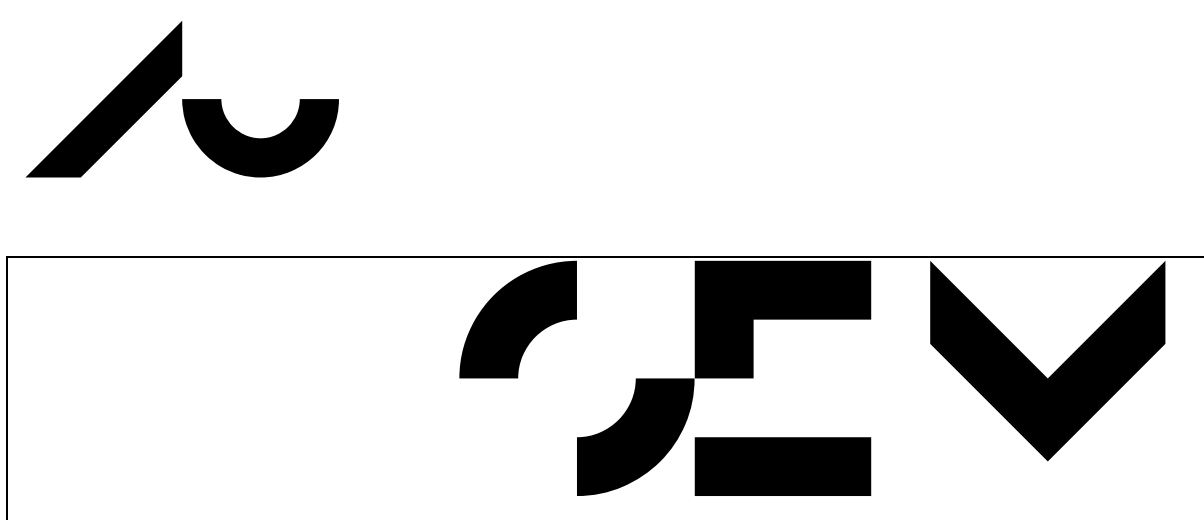

Economics Working Paper

2010-11

\title{
Income and the use of prescription drugs for near retirement individuals
}

Søren Leth-Petersen and Niels Skipper

School of Economics and Management

Aarhus University

Bartholins Allé 10, Building 1322

DK-8000 Aarhus C - Denmark

Phone +4589421610

Mail: oekonomi@econ.au.dk

Web: www.econ.au.dk 


\title{
Income and the use of prescription drugs for near retirement individuals
}

\author{
Søren Leth-Petersen ${ }^{\dagger}$, Niels Skipper ${ }^{*}$
}

July 2010

\begin{abstract}
:
Understanding how demand for prescription drugs responds to changes in income is important for assessing the welfare consequences of reforms affecting income. This becomes more imminent as age progresses, because the use of prescription drugs and the associated budgetary burden increases dramatically from about age 55. In this paper we estimate how demand for prescription drugs varies with income for a sample of near retirement individuals. Estimating the prescription drug demand response to income changes is complicated because an important explanatory variable, the health capital, is unobserved, and because demand is potentially dynamic, for example because some drugs are habitual. The analysis is based on a novel panel data set with information about purchase of prescription drug demand for a very large number of Danish individuals over the period 1995-2003. Our preferred model that takes into account the aforementioned complications performs better in an external validation test than models that can be estimated on cross section data. Results indicate that demand does respond to variations in income and that reforms affecting income therefore will affect the use of prescription drugs.
\end{abstract}

JEL classification: $\mathrm{I11}$, I18

Keywords: Prescription drugs demand; income; near retirement.

$\dagger$ Department of Economics, University of Copenhagen, Øster Farimagsgade 5, building 26, DK-1353 Copenhagen. Email: soren-leth-petersen@econ.ku.dk.

*School of Economics and Management, Aarhus University, Bartholins Allé 10, Building 1323, 3, DK-8000

Aarhus. Email: nskipper@econ.au.dk. 


\section{Introduction}

There is great interest in knowing if the demand for prescription drugs responds to changes in people's incomes. This is because such elasticities are relevant for the design of policies aiming at improving the health status. For example, Deaton and Paxson (1998) show that income is correlated with self reported health. Little is known about the causes of this link, but it may be related to different patterns of drug expenditures. If this is the case, then reforms affecting income may also affect the health through drug use. Moreover, knowing the income elasticity of demand for prescription drugs is important for assessing welfare effects of tax reforms and other reforms affecting disposable income.

The objective of the paper is to estimate how demand for prescription drugs varies with income for a sample of near retirement individuals. The focus is on near retirement individuals because demand for prescription drugs increases dramatically from around age 55 and because this group experiences considerable income variations around the point of retirement. In contrast, younger people also experience considerable income variations but have low drug demand. Few have previously worked on this topic. Moran and Simon (2006) estimate how the demand for different types of prescription medications varies with income. On a cross section of retirees they compare people that have different social security payments solely because they were born in different years. They find that an increase in Social Security income by US\$1,000 increases the number of prescription medications used by 0.55 per month. Alan et al. (2002 and 2005) analyze senior and non-senior prescription drug demand and investigate the redistributive effects of a large scale prescription drug program. They do this (among other things) by estimating Engle curves on the Canadian Family Expenditure Survey consisting of repeated cross sections and investigating how Engel curve relationships differ between periods where the subsidy program is in operation and other periods where it is not.

Estimating how prescription drug demand responds to income variations is complicated by the fact that demand for drugs is likely to be related to the health capital which is generally unobserved and can often at best only be proxied by including measures of self-reported health when analyzing cross section data. Controlling for health capital is important because the level of health capital tends to be related to marginal productivity so that individuals with a higher level of health capital also have a higher level of human capital. Therefore, comparing demand of 
individuals with high income with that of individuals with low income in order to estimate Engle curves is likely to (also) reflect selection effects. Moreover, the use of prescription drugs is likely to be endogenous to the extent that consuming drugs improves health and thereby earnings capacity and income. Another issue relates to the dynamic aspects of drug demand. Some drugs are habitual and the consumption may be the consequence of treatments that extend beyond the period for which the data is collected, typically one year. At best, the above mentioned papers take in to account one of these issues. We argue that it is crucial to control for all of them when modeling the dependence of demand for prescription drugs on income. In fact leaving out one of these elements from the analysis can lead to seriously biased Engle curve estimates.

The analysis presented in this paper is based on a panel data set with information about $20 \%$ of the Danish population under the age of 70 . This data set has some unique features that are crucial in this context. Most importantly, and unlike any other data set that we know of, it holds person level panel information about demand for prescription drugs for the period 1995-2003. This enables us to model the dynamic structure of demand and to take account of person-level fixed unobserved factors as well as correlation between income and the idiosyncratic error term. Moreover, covering $20 \%$ of the Danish population the data set is very large compared to expenditure surveys or other data sets with information about the demand for prescription drugs. This enables us to consider prescription drug demand for subsets of the population without relying on small samples. We use this feature to illustrate that the effect of income on the demand for prescription drugs can vary significantly across different levels of income.

In the main analysis we focus on persons aged $55-65^{1}$, i.e., persons near retirement. The results show a strong relationship between income and the demand for prescription drugs when estimated on a cross section. However, taking into account the dynamic structure of demand as well as fixed factors controlling for individual specific levels of health capital is very important in this context. Applying an appropriate panel data model weakens this relationship considerably. This suggests that Engle curve relationships estimated off cross section data may lead to biased estimates of the Engle curve relationship and that caution is warranted when giving such estimates a behavioral interpretation, i.e., as an estimate of the demand response to a change in

\footnotetext{
${ }^{1}$ Observations for age groups 66-69 are reserved for an external validation exercise where the estimated model's ability to capture the adjustment in demand following the change in income from age 66 to 68 is investigated.
} 
income. This knowledge is essential for policy makers trying to design policies that affect the level of disposable income. If polices are based on relationships estimated on cross section data, then the effects on demand from welfare reforms can appear substantial when they in fact are small. Results from this study, however, still suggest that reforms affecting income, for example reforms of the public pension provision, will affect the demand for prescription drugs.

The remainder of the paper is organized as follows. In the next section we sketch the empirical problem and suggest a solution to it. Section 3 presents the data and shows how demand differs between young and old persons by estimating nonparametric Engle curves on cross sections from our gross data set. Section 4 presents a multivariate analysis in which we try to take in to account potentially confounding factors. In this section we also show how the results differ between young and old persons. In section 5 we attempt to validate our model for the near-retirement sample by checking its ability to predict the adjustment in demand following the first receipt from a universal government public pension scheme that is awarded irrespectively of whether the individual has labor income. The idea is that this leads to an exogenous change in income that is arguably unrelated to the development in health status. Section 6 sums up and concludes.

\section{Method}

There are several complications associated with estimating Engle curves for prescription drug demand. First, demand is potentially driven by unobserved factors that we refer to as health capital, cf. Grossman (1972). More health capital leaves the individual more resistant to adverse health events and individuals equipped with more health capital are assumed to have a lower level of consumption of prescription drugs. The stock of health capital is likely heterogeneous across the population where some individuals are generally equipped with a high level of health capital and others with a low level of health capital. In general, health capital will be nonseparable from human capital so that an adverse shock to the health capital also produces an adverse shock to earnings. The effects of such adverse shocks can be mitigated by consuming drugs that restore the health capital and stimulate productivity again. Another complication relates to the potential dynamic aspects of drug demand. Drug demand potentially follows a dynamic process because demand is habitual, but it can also reflect that the data are collected over a time frame that does not match the time frame of the treatment. This occurs, for example, 
when data are collected from January to December but the treatment program runs from November to March. In this section we formulate a demand model that can handle these concerns.

Consider the following demand function.

$$
s_{i t}=\beta_{0}+\beta_{1} s_{i t-1}+\beta_{2} y_{i t}+\beta_{3} y_{i t}^{2}+\beta_{4} x_{i t}+\mu_{i}+u_{i t}
$$

where $i=1, \ldots, N$ is the person identifier and $t$ identifies the period of observation. $s_{i t}$ is the share of income allocated to prescription drugs for individual $i$ in year $t$, and $s_{i t-1}$ is the expenditure share for person $i$ measured in the previous period. $y_{i t}$ is the natural $\log$ of disposable income. Following the standard in the demand literature we include a quadratic term in log-income, Banks, Blundell and Lewbel (1997), to allow the Engle curve to be nonlinear. $x_{i}$ is a vector of control variables including age, sex, marital status, number of children, immigrant/native, education, occupation and geographical location. $\beta_{0}, \beta_{1}, \beta_{2}, \beta_{3}, \beta_{4}$ are parameters to be estimated, but the focus in this paper is on the estimation of the income response, and $\beta_{2}, \beta_{3}$ are therefore the parameters of interest in this study. Prices are subsidized according to a complicated scheme that is generally independent of the level of income, and we therefore ignore price effects ${ }^{2}$, see Simonsen et al. (2010). $\mu_{i}$ is an unobserved effect that is specific to person $i$, and $u_{i t}$ is an error term that may vary across time periods and individuals.

We think of $\mu_{i}$ as capturing innate unobserved health or the part of the health capital that is approximately fixed over the time span where we observe a person in our data set. Because health capital is potentially nonseparable from human capital, $\mu_{i}$ is potentially correlated with $y_{i t}$ and our estimation method should address this. $u_{i t}$ includes unanticipated adverse health shocks. An adverse health shock can generate a drop in income. The consumption of drugs on the other hand can help restore the income level. $u_{i t}$ is therefore potentially correlated with $y_{i t}$. Estimating

\footnotetext{
${ }^{2}$ Income-tested subsidies are granted by municipalities. The empirical analysis is insensitive to exclusion of individuals receiving these subsidies. Additionally, in 2000, the subsidy scheme was reformed, so as to increase co payment. This affected people with low levels of prescription drug use most. In section 4 we shall perform a sensitivity check so as to make sure that this reform does not bias the results.
} 
(1) by methods assuming orthogonality of the regressors is therefore not likely to produce consistent estimates of $\beta_{1}, \beta_{2}, \beta_{3}$. Moreover, the fact that $s_{i t-1}=\beta_{0}+\beta_{1} s_{i t-2}+\beta_{2} y_{i t-1}+$ $\beta_{3} y_{i t-1}^{2}+\beta_{4} x_{i t-1}+\mu_{i}+u_{i t-1}$ implies that $\operatorname{cov}\left(s_{i t-1}, \mu_{i}\right)>0$ in (1). Estimating the parameters of (1) by OLS will therefore produce biased estimates not only of $\beta_{2}, \beta_{3}$ but also of $\beta_{1}$ if $\mu_{i}$ is an important factor in explaining $s_{i t}$.

To address these problems, we exploit the panel structure of the data and invoke the assumption that $\operatorname{cov}\left(u_{i t}, u_{i t-1}\right)=0, l=1, \ldots, T-1$. This assumption is testable and it allows us to define a set of instrumental variables that enable us to solve the problems associated with estimating (1).

Consider first the solution to the problem associated with estimating $\beta_{1}$. Note that $\operatorname{cov}\left(s_{i t-1}, \mu_{i}\right)>0$ but $\operatorname{cov}\left(\Delta s_{i t-1}, \mu_{i}\right)=0, l \geq 1$. This suggests that $\Delta s_{i t-l}, l \geq 1$ can be used as instrumental variables for $s_{i t-l}$ in equation (1). Moreover note that $\operatorname{cov}\left(y_{i t}, u_{i t}\right) \neq 0$ and $\operatorname{cov}\left(y_{i t}, \mu_{i}\right) \neq 0$ but that $\operatorname{cov}\left(\Delta y_{i t-l}, u_{i t}\right)=\operatorname{cov}\left(\Delta y_{i t-l}, \mu_{i}\right)=0, l \geq 1$. This suggest that $\Delta y_{i t-l}, l \geq 1$ can be used as instrumental variables for $y_{i t}{ }^{3}$

An alternative approach to addressing the problems associated with estimating the parameters of (1) starts out solving the endogeneity problems arising because of the unobserved individual specific effect $\mu_{i}$. To do this, consider a first differenced version of (1)

$$
\Delta s_{i t}=\beta_{0}+\beta_{1} \Delta s_{i t-1}+\beta_{2} \Delta y_{i t}+\beta_{3} \Delta y_{i t}^{2}+\beta_{4} \Delta x_{i t}+\Delta u_{i t}
$$

In equation (2) still $\operatorname{cov}\left(\Delta u_{i t}, \Delta s_{i t-1}\right)=\operatorname{cov}\left(\Delta u_{i t}, \Delta u_{i t-1}\right)=-\operatorname{cov}\left(u_{i t-1}^{2}\right)<0$, and OLS on (2) will still produce biased instruments. $\beta_{1}$ can be consistently estimated by applying GMM/IV using $s_{i t-l}, l=2, \ldots, T-2$ as an instrument for $\Delta s_{i t-1}$. This follows the insights of Andersen and Hsiao (1981) and Arellano and Bond (1991). We still need to accommodate the potential endogeneity of $\Delta y_{i t}$ (and $\Delta y_{i t}^{2}$ ). This arises because:

\footnotetext{
${ }^{3}$ A static demand relation with a linear Engle curve is nested in (1). In the result section we shall estimate such a version of the model and compare its performance with the performance of (1) taking into account the endogeneity of $s_{i t-1}, y_{i t}$, and $y_{i t}^{2}$.
} 
$\operatorname{cov}\left(u_{i t}, y_{i t}\right) \neq 0 \Rightarrow \operatorname{cov}\left(\Delta u_{i t}, \Delta y_{i t}\right)=\operatorname{cov}\left(y_{i t}, u_{i t}\right)+\operatorname{cov}\left(y_{i t-1}, u_{i t-1}\right) \neq 0$

(and correspondingly for $\left.\Delta y_{i t}^{2}\right)$. We note that $\operatorname{cov}\left(u_{i t}, y_{i t-l}\right)=\operatorname{cov}\left(u_{i t-1}, y_{i t-l}\right)=0, l=$ $2, \ldots, T-2$, and that income lagged twice or more therefore can be used as instruments for $\Delta y_{i t}$.

Arellano and Bover (1995) and Blundell and Bond (1998) suggest combining equations in levels, (1), and equations in first differences, (2), in order to obtain a more efficient estimator. When the autoregressive parameter is close to unity, i.e., the series is highly persistent, the lagged levels become weak instruments in the differenced equations and yields biased estimates. Further, if the variance of the individual fixed effect is large relative to that of the idiosyncratic error-term, using only equations in first differences will yield biased estimates. Even for low values of the autoregressive parameter, Monte Carlo simulations have shown that combining equations in differences and levels implies significant efficiency gains; see Blundell and Bond (1998). Our preferred estimator does exactly that ${ }^{4}$.

\section{Data}

We use administrative data provided by Statistics Denmark. The data set contains information about a random sample of $20 \%$ of all Danish individuals in the period from 1995-2003. We construct a balanced panel of individuals aged 18 to 69 including 681,837 individuals. In the estimation part of the paper we focus on individuals between 55 and 65 years. 203,911 people in the data set are aged 55-65 at some point in the panel. For each individual in the sample we know the complete history of prescription drug purchases including date, prices etc. These data are augmented with socio-economic information on age, sex, marital status, number of children, immigrant/native, education, occupation and geographical location. The data set has one shortcoming: it does not hold information on diagnosis or other types of in-or out-patient care.

\footnotetext{
${ }^{4}$ One additional complication is that the dependent variable is censored at zero since some persons do not consume drugs. Not taking censoring into account can be associated with inconsistent estimates. No estimator exists that simultaneously handles the endogeneity problems presented above while addressing the censoring issue. In section 5 we show evidence that the censoring problem is likely to be less important than the endogeneity problems, and we therefore proceed ignoring the censoring problem.
} 


\section{Descriptive Statistics}

In table 1, descriptive statistics on a subset of the variables in the data set is presented. There are marginally more women than men in the 55-65 age brackets as well as for the full sample. The mean income for the full sample is DKK 255,058 and DKK 246,532 for the 55-65 year olds.

\section{[Insert table 1 here]}

In figure 1, a local polynomial regression of the drug expenditure share on age is depicted. As can be seen, there is a strong, positive relationship between the two. This may be explained by a deteriorating health status at old age, but as figure 2 shows, the average income is also falling from age 60 and onwards. That is, this does not necessarily imply that the elderly consume more drugs, only that they allocate a larger fraction of their income to drug consumption. Inspection of the actual levels (not reported) reveals that demand is quantitatively increasing markedly from around age 50 .

\section{[Insert figure 1 here]}

\section{[Insert figure 2 here]}

The non-parametric Engel curve for total prescription drug consumption is graphed in figure 3. As can be seen, there is a negative, monotonic relationship between the expenditure share and income.

\section{[Insert figure 3 here]}

Note that a quadratic form seems to be able to capture the nonlinearities in drug demand. Given that the elderly have a higher average expenditure share, the Engel curve relationship might differ over age groups. In figure 4, two separate Engel curves are depicted: one for individuals below 55 ('young') and one for individuals aged 55 or above ('old'). The shapes of the two relations are very similar, but the levels are different (note the different scales). This suggests that the older part of the age distribution reacts more to income changes. ${ }^{5}$

\section{[Insert figure 4 here]}

\footnotetext{
${ }^{5}$ Deaton and Paxson (1998) also find that the income-health correlation becomes stronger as age progresses.
} 


\section{Results}

The estimation results for the sample of the 55 to 65 year-olds are reported in table 2. Columns (1) and (2) are OLS estimations of the Engel curves. A linear income term is included in (1), and income squared is included in (2). Both show a negative relationship between income and the expenditure share just as we found in the non-parametric Engel curve in figure 3. Columns (3) and (4) are the same as (1) and (2) but with income being treated as endogenous. Lagged differences of the endogenous explanatory variable are used as instruments; see section 2 . In the linear case, treating income as endogenous does not affect the parameter estimates. When we include income squared, however, treating income as endogenous reduces the point estimates to both income terms. Note that the test of the overidentifying restrictions is rejected neither in (3) nor (4) at the usual levels of significance, suggesting that instruments are valid.

[Insert table 2 here]

Column (5) holds the OLS results for the estimation with income, income squared and a lagged dependent variable as key explanatory variables. When compared to (2), including the lagged dependent variable reduces the numerical size of the point estimates of the income terms to about the half. The AR parameter is 0.62 indicating a high degree of state dependence. The OLS estimate of the AR parameter is known to be upward biased, Bond (2002). The within groups estimate of the AR parameter in column (6) is 0.12. This estimate is downwards biased, and so the true degree of persistence in demand is bounded by the estimates presented in columns (5) and (6). In any case, estimating the relation by OLS or within groups produces biased estimates of the AR parameter as well as the coefficients to the income terms.

The results for the GMM-SYS estimator that takes into account the endogeneity of the lagged dependent variable but still treating income as exogenous is presented in column (7) where $s_{i, t-2}, s_{i, t-3}, s_{i, t-4}$ are used as instrumental variables for the lagged dependent variable in the difference equations and $\Delta s_{i, t-1}$ is used as instrument for the lagged dependent variable in the level equations. In this model, the autoregressive parameter is more than halved $(0.256)$ compared to the OLS counterpart in (5). The GMM estimate of the AR parameter lies between the OLS and within groups estimates in column (5) and (6). Also, this is an informal test that the GMM-estimator of the AR parameter is not misspecified. The coefficients to the income terms 
are comparable to those of the static model in (2). The Arellano-Bond test for no autocorrelation in the first differenced error-term is also reported. We report the tests of $1^{\text {st }}, 2^{\text {nd }}$, and $3^{\text {rd }}$ order autocorrelation. The identifying assumption of serially uncorrelated errors would lead to negative first-order serial correlation in the differenced errors, but no significant second or higher order serial correlation should be present. The test statistics shows significant $1^{\text {st }}$ order autocorrelation, but no significant $2^{\text {nd }}$ or $3^{\text {rd }}$ order autocorrelation suggesting that the model is not misspecified. The Sargan test of overidentifying restrictions is rejected though. This latter test however has been shown to perform poorly; see Arellano \& Bond (1991).

We also wish to control for the possible endogeneity of income in the GMM-SYS setup by using lagged levels and differences as instruments; see column (8). Specifically, we instrument the income terms with $y_{i, t-2}, y_{i, t-3}, y_{i, t-4}$ in the difference equations ${ }^{6}$, and $\Delta y_{i, t-1}$ is used as instrument in the levels equations (same procedure is used for the squared income term). The AR parameter is very close to that of (7), and we are not able to distinguish between the two statistically. However, there is a significant reduction in the numerical size of the point estimates to both income terms. They are now both individually statistically insignificant, yet jointly significant. The Sargan test still rejects the overidentifying restrictions, but the Arellano-Bond test of no second-order auto-correlation in the first differenced error-term is not rejected at the $5 \%$ level. The estimates presented in column (8) take into account all the complications that we listed in section 2, and this is our preferred set of estimates. We note that the Engle-curve relationship is considerably weaker than what is found when estimating it off cross section data whether taking into account the endogeneity of income or not.

The results from this study are comparable to the results obtained by Alan et al. (2005). They estimate static Engle curves for non-senior households on Canadian expenditure survey data and report $^{7}$ mean budget share elasticities with respect to income in the range $[-0.0057 ; 0]$ with more significant responses for lower income households. In this study the model with quadratic and instrumented income terms, column 4 in table 2, produces mean budget share elasticities with respect to income in the range $[-0.019 ;-0,012]$ and in the range $[-0.0057 ;-0.0036]$ for the

\footnotetext{
${ }^{6}$ Including further lags do not affect the results.

${ }^{7}$ In table 4, page 141.
} 
preferred model, column 8 table 2. Also in our case the response is stronger for lower incomes. The Engle curve estimates from this study are in general not far from the estimates obtained in their study, and the estimates from our dynamic model are closer to their estimates. However, our study suggest that estimates obtained from a dynamic model estimated on panel data tend to suggest smaller responses than what is indicated from the estimates obtained from a static model. The dynamic aspect may be important for describing the adjustment in demand to changing incomes. We shall return to this in section 5.

Before closing this section, we note that while we prefer the estimates presented in column (8), the IV estimates based on cross section data presented in column (4) pass the Sargan test. This suggest that researchers who are equipped only with cross section data while trying to estimate Engle curves for prescription drug demand will take such models to be well specified. Our results suggest that this may not be the case. In section 5 we shall compare the performance of the models in an external validation test in order to provide additional evidence of what model is to be preferred. Before doing this, we present some robustness checks.

\section{Sensitivity Analysis}

\section{Full sample estimation}

Figure 4 pointed towards the possibility that the Engel curve relation is not stable over different age-groups. We therefore estimate our set of models on the entire group of people below the age of 65 . The results are displayed in table 3.

\section{[Insert table 3 here]}

If we compare each specification to the counterpart in table 1, the income terms generally have the same sign, but the absolute value has decreased by around 50\%. For our preferred specification, GMM-SYS with endogenous income, the estimates are still very small, and the individual coefficients are not statistically significantly different from zero. That is, based on a simple comparison of the individual coefficients, we are not able to distinguish the results generated from the large sample from the results generated from the small sample for the GMMSYS model with endogenous income. However, the signs of the individual coefficients have 
changed. Note that the estimates of the autoregressive parameter reported in table 3 are comparable to those in table 2. Further, all the specification tests regarding validity of the instruments are rejected at trivial levels of significance. This is also the case for the ArellanoBond test of no second-order autocorrelation in the first differenced residuals for both GMMSYS models. The general pattern showing that the correlation between income and drug expenditure gets stronger as age progresses is consistent with the findings of Deaton and Paxson (1998) showing that the correlation between self reported health and income becomes stronger with age when persons younger than 70 are considered.

\section{Censoring}

Not all people have expenditures on prescription drugs. This means that some of the observations are censored at zero. In the 55-65 sample $23 \%$ of the observations are censored ${ }^{8}$, and this may introduce bias in the estimates presented earlier. Unfortunately no estimator exists that can simultaneously handle all the complications listed in section 2 while also addressing the censoring issue, see Arellano and Honoré (2003). However, to obtain a feel for the importance of censoring we estimate the two static Engel curve relations (corresponding to the results presented in columns (1) and (2) in table 2) using a Tobit-model and compare these estimates to the OLS counterparts. These results are shown in table 4.

\section{[Insert table 4 here]}

The OLS and Tobit estimates are very similar; the point estimates are only marginally different. The coefficients in the linear specifications are however statistically significantly different, but this is not the case when the squared term is included. It is questionable whether the differences in the estimates offer any economic significance. We take this as suggestive evidence that the endogeneity issues outlined in section 2 are of greater importance than the censoring.

\footnotetext{
${ }^{8}$ In the sample including all persons aged 65 or younger the degree of censoring is $26 \%$.
} 


\section{Individual versus household income}

So far, the analysis has been based on individual income. It is likely that couples will insure each other mutually. To shed light on this, we estimate the model using the income of the household instead of the individual income; see table 5. The results show that the estimated coefficients for the preferred model are very similar to the results using only individual income. We are not able to distinguish between the coefficients statistically, and the point estimates are so small that the difference is of no economic significance. We note, however, that the income terms are jointly insignificant when using household income. Further, the Arellano-Bond test for no second order autocorrelation in the first-differenced errors is rejected.

\section{[Insert table 5 here]}

\section{Gender differences}

Another dimension along which results can potentially vary is gender. On average women have lower income and a higher absolute level of drug use. Results for subsamples of men and women are presented in tables 6 and 7. The income response estimates are individually insignificant for both women and men. The income parameters are jointly significant for women, but not for men. However, plotting the estimated Engle curve relationship (not reported) suggests that the differences are of no economic importance.

[Insert table 6 here]

[Insert table 7 here]

\section{Reimbursement reform in 2000}

In 2000 the general population subsidy scheme for prescription drugs in Denmark was changed. Before 2000, all drugs that were qualified received a fixed percentage subsidy. After the reform the drug subsidies became a function of individual level consumption, offering no subsidies for low level of expenditures but with an increasing subsidy rate in yearly total expenditures; see 
Simonsen et al. (2010). Specifically, drug expenditure less than DKK 500 was not subsidized but for expenditures above DKK 500, a 50\% subsidy is granted, increasing to 75\% at DKK 1200 and so forth. This implied a higher copayment for people with relatively small expenditure levels. To shed light on the effects of this reform for the estimation of the income response of demand, we estimate the preferred model with an indicator on pre-post reform status and interact it with the income parameters. These effects turn out to be very small and statistically insignificant (results not reported). Further, as individuals with lower consumption pay relatively more for their drugs under the new regime, we estimate the model with and indicator that is equal to one if an individual is in the post-reform period and had an expenditure level less than DKK 1,000 in 1999 and zero otherwise. This indictor is then interacted with the income terms. These interaction terms are statistically significant, but the estimated coefficients are very small and they do not provide any meaningful economic significance.

\section{External Validation}

Several of the models that we presented parameter estimates for in table 2 of section 4 for age groups 55-65 pass standard specification tests. Specifically, we found that the static model with a quadratic Engle curve that was instrumented, column (4), passed the Sargan test for overidentifying restrictions, while our preferred model, column (8), did not. ${ }^{9}$ As mentioned, the Sargan test is known to have low power, but is often uses anywa as a standard specification test in cross section studies with endogenous regressors and overidentifying restrictions. Short of having access to data as rich as ours this could (justly) lead researchers to assume that such a model is well specified. Yet, we have found that static models can produce results that differ substantially from those of dynamic models.

In order to investigate further the benefits of modeling drug demand using our proposed dynamic specification we conduct an external validation test in the spirit of Todd and Wolpin (2006). The idea of the test is to use the estimated models to make out-of-sample predictions of the demand response to an exogenous change in income. An estimated demand model ideally provides

\footnotetext{
${ }^{9}$ This model did pass the more focused test for no autocorrelation in errors.
} 
information about how demand responds to a change in income and not about how income responds to a change in demand. In our context demand could cause income if, for example, an adverse health shock leads to increased drug expenditures and retirement thereby lowering income. An external validation experiment should therefore examine the effect of a change in income that is not used for estimating the model and is not the consequence of a health shock. We argue that a feature of the Danish public pension system provides exactly this type of variation for a subsample of the persons entering the sample used in the estimations.

The income of retirees typically consists of one or more of three income sources: (1) Public pension (2) private pension and (3) labor market pensions. While private and labor market pensions are potentially related to historic health and earnings capacity, public pension is granted to all Danish citizens from the day they turn 67 irrespective of their previous, current and future labor market participation and health status ${ }^{10}$. In 2000, the yearly amount paid out was DKK 72,096 (ca. US\$ 12,000) per person if cohabiting or married and DKK 98,700 (approximately US\$16,500) for singles.

The public pension scheme is supplemented by an early retirement scheme making it possible to retire at some point in the age interval 60-66. The yearly amount paid out in this program is DKK 148,200 (approximately US\$ 24,700) in 2000. Between the ages 60-66, this amount is to be paid out for the first $2 \frac{1}{2}$ years in the program, and hereafter reduced to DKK 121,420 (approximately US\$20,200), to provide an incentive to postpone retirement. The early retirement scheme was introduced in 1979, and the introduction was motivated as a scheme giving the opportunity for physically worn down individuals to retire earlier. Using US data, Rust \& Phelan (1997) find that low health status is associated with the decision to opt for early retirement. Hence, we cannot be sure that early retirement and the accompanying change in income is not related to an adverse change in health.

The external validation experiment investigates whether the estimated models are able to explain how demand develops from age 66 to age 68 where the public pension is granted to all citizens irrespective of their health. We consider the change in income from 66 to 68 rather than from 66 to 67 for a two reasons. First, the income data covers the calendar year but the public pension is

\footnotetext{
${ }^{10}$ In what follows, we describe the rules in effect at the time covered by the data.
} 
supplied from each person's birthday and therefore does not follow the calendar year for most individuals. The full effect of the public pension is therefore not recorded in the data until age 68. Second, private capital pensions are also paid out at age 67 and this may give a transitory income that does not reflect the effect of the public pension.

\section{[Insert figure 5 here]}

We predict the expenditure share at age 66 and 68 respectively and calculate the difference ${ }^{11}$. In figure 5, the model predictions are plotted together with the associated income changes. The average income drop from age 66 to 68 is about $6.3 \%$. However, the spread is large, and the graph has therefore been trimmed such that the top and bottom $10 \%$ of the income changes have been left out. The graph shows the actual expenditure share changes together with those predicted by the linear static model where income is treated as endogenous (specification (3)) and our preferred GMM-SYS estimator where income is treated as endogenous. As can be seen, the predictions from the GMM-SYS estimator are much closer to the actual changes compared to the linear specification. To assess the statistical significance we bootstrapped the procedure to provide a confidence band for the predictions. As can be seen, the actual changes lie within the confidence band of the preferred model. The confidence bands of the linear static model (not reported) are so wide that it is not possible to distinguish between the two models. The static model with a quadratic income term yields predictions similar to those of the linear static model, both with income treated as exogenous and endogenous (not reported).

Individuals who have retired before age 67 in many cases experience relatively small changes in income when the public pension system kicks in. To investigate whether the model can handle significant income changes, we also perform the exercise for the subsample of persons who are recorded with labor income at age 66 and therefore have not opted for the early retirement scheme, and are still present in the sample when 68. This amounts to 9,083 individuals. Many of these people will retire at age 67 and this may be a consequence of the public pension. However, for this group the decision to retire and the accompanying change in income is not likely to be

\footnotetext{
${ }^{11}$ When we predict the expenditure share at age 68 , we need to know the expenditure share at age 67 when we have a lagged dependent variable in the model. As this variable would not be observed in a real experiment, we use the expenditure share at age 66 instead.
} 
related to a discretionary change in health. Their average drop in income is 5.3\% from 66-67, $15.3 \%$ from $66-68$ and $18.0 \%$ from 66-69. This suggests that the income change from age 66-68 is significant and that it reflects the permanent income drop associated with retirement. Density plots of the income changes (not reported) confirm that this is not driven by extreme observations. Again, we predict the expenditure share at age 66 and 68 respectively and calculate the difference. In figure 6 , the model predictions are plotted together with the associated income changes. Also, this graph has been trimmed such that the top and bottom $10 \%$ of the income changes have been left out, and it shows the actual expenditure share changes together with those predicted by the linear static model where income is treated as endogenous (specification (3)) and our preferred GMM-SYS estimator where income is treated as endogenous. The graph clearly shows that the predictions from the GMM-SYS estimator are much closer to the actual changes than the prediction from the linear specification.

[Insert figure 6 here]

We take the evidence from the external validation as suggestive that our preferred model of prescription drug use captures the behavioral adjustment in drug demand following income changes better than a standard cross section model.

\section{Summary and Conclusion}

In this paper we present an analysis of how the demand for prescription drugs is affected by variations in income. Estimation of Engle curve relationships for the demand for prescription drugs is complicated because a central explanatory variable, the health capital, is unobserved and because demand has dynamic aspects, for example because some drugs are habitual.

The analysis is based on a novel panel data set with information about purchase of prescription drug demand for a very large number of Danish individuals over the period 1995-2003. Our analysis focuses on a pre-retirement group aged 55-65 where both average demand for prescription drugs and income vary markedly. Our preferred model that takes in to account the 
aforementioned complications performs better in an external validation test than models that can be estimated on cross section data. Results indicate that demand does respond to variations in income but less so than what is suggested by cross section estimates. This suggests that reforms affecting incomes, for example reforms of public pension provision, will affect demand for prescription drugs.

\section{Acknowledgements}

We greatly appreciate valuable comments and suggestions from Martin Browning and Michael Svarer. 


\section{References}

Anderson, T. W. \& Hsiao, C. (1981); Estimation of Dynamic Models with Error Components; Journal of the American Statistical Association, 76(375), pp. 598-606.

Alan, S. \& Crossley, T. \& Grootendorst, P. \& Veall, M.R. (2002); The effect of drug-subsidies on out-of-pocket prescription drug expenditures by seniors: regional evidence from Canada; Journal of Health Economics, 21, pp. 805-826

Alan, S.; Crossley, T.; Grootendorst, P.; Veall, M.R. (2005); Distributional effects of 'general population' prescription drug programs in Canada; Canadian Journal of Economics, 38, 1, pp. 128-148.

Arellano, M. \& Bond, S. (1991); Some Tests of Specification for Panel Data: Monte Carlo Evidence and an Application to Employment Equations; Review of Economic Studies, 58, 277297.

Arellano, M. \& Honoré, B. (2001); Panel Data Models: Some Recent Developments; in J. J. Heckman and E. Leamer (eds.): Handbook of Econometrics, Vol. 5, Chapter 53, North-Holland, pp. 3229-3296

Banks, J. \& Blundell, R. \& Lebwel, A. (1997); Quadratic Engel Curves and Consumer Demand; The Review of Economics and Statistics; Vol. LXXIX, no. 4, pp. 527-539

Blundell, R. \& Bond, S. (1998); Initial Conditions and Moment Restrictions in Dynamic Panel Data Models; Journal of Econometrics, 87, 115-143.

Bond, S. (2002); Dynamic panel data models: a guide to micro data methods and practice; Portuguese Economic Journal, 1, 141-162.

Deaton, A. S. \& Paxson, C. H. (1998); Aging and Inequality in Income and Health; The American Economic Review, Vol. 88, No. 2, Papers and Proceedings, pp. 248-253.

Grossman, M. (1972); On the Concept of Health Capital and the Demand for Health; Journal of the Political Economy, Vol. 80, pp. 223-255.

Moran, J. R. \& Simon, K. I. (2006); Income and the Use of Prescription Drugs by the Elderly; Journal of Human Resources, XLI, 2, pp. 411-432.

Rust, J. \& Phelan, C. (1997); How Social Security and Medicare Affect Retirement Behavior in a World of Incomplete Markets; Econometrica, Vol. 65, No.4, pp.781-831.

Simonsen, M. \& Skipper, L. \& Skipper, N (2009); Price Sensitivity of Demand for Prescription Drugs: Exploiting a Regression Kink Design. Economics Working Papers no. 2010-03, School of Economics and Management, Aarhus University. 
Todd, P. \& Wolpin, K. (2006); Assessing the Impact of a School Subsidy Program in Mexico: Using a Social Experiment to Validate a Dynamic Behavioral Model of Child Schooling and Fertility; American Economic Review, 96(5), pp. 1384-1417. 
Tables to be inserted in the text

TABLE 1

\begin{tabular}{|c|c|c|c|}
\hline \multicolumn{4}{|c|}{ DESCRIPTIVE ST AT IST ICS } \\
\hline \multicolumn{4}{|l|}{ age $<70$ years } \\
\hline & Mean & St.dev. & Median \\
\hline Age & 43.91 & 13.22 & 43 \\
\hline Gender & 0.4997 & 0.50 & 0 \\
\hline Income & $255,057.60$ & $187,138.40$ & $232,021.90$ \\
\hline Log income & 12.28 & 0.63 & 12.35 \\
\hline Household income & $441,473.70$ & $618,201.80$ & $420,721.00$ \\
\hline Log hous ehold income & 12.80 & 0.68 & 12.95 \\
\hline \multirow{2}{*}{$\begin{array}{l}\text { Expenditure share } \\
\text { Obs. }\end{array}$} & 0.0037 & 0.0135 & 0.0008 \\
\hline & $5,518,532$ & & \\
\hline \multicolumn{4}{|l|}{$55 \leq$ age $\leq 65$ years } \\
\hline & Mean & St.dev. & Median \\
\hline Age & 59.47 & 3.14 & 59 \\
\hline Gender & 0.4962 & 0.50 & 0 \\
\hline Income & $246,532.40$ & $221,648.00$ & $204,373.50$ \\
\hline Log income & 12.21 & 0.68 & 12.23 \\
\hline Household income & $422,129.60$ & $315,622.90$ & $368,957.00$ \\
\hline Log hous ehold income & 12.77 & 0.62 & 12.82 \\
\hline Expenditure share & 0.0059 & 0.0183 & 0.0017 \\
\hline Obs. & $1,043,423$ & & \\
\hline
\end{tabular}

Selected descriptive statistics by age category. 
TABLE 2

\begin{tabular}{|c|c|c|c|c|c|c|c|c|}
\hline \multicolumn{9}{|c|}{ ESTIMATION RESULTS: 55-65 YEARS } \\
\hline & OLS & OLS & $\begin{array}{c}\text { IV } \\
\text { 2SLS } \\
\end{array}$ & $\begin{array}{c}\text { IV } \\
2 S L S \\
\end{array}$ & OLS & $\begin{array}{r}\text { WITHIN } \\
\text { GROUPS } \\
\end{array}$ & $\begin{array}{c}\text { GMM-SYS } \\
\text { EXOG. } \\
\end{array}$ & $\begin{array}{c}\text { GMM-SYS } \\
\text { ENDOG. }\end{array}$ \\
\hline$s$ & $(1)$ & $(2)$ & (3) & $(4)$ & $(5)$ & (6) & $(7)$ & $(8)$ \\
\hline INCOME & $\begin{array}{l}\mathbf{- 0 . 0 1 1} \\
(.0002)\end{array}$ & $\begin{array}{l}\mathbf{- 0 . 0 5 3} \\
(.0036)\end{array}$ & $\begin{array}{l}\mathbf{- 0 . 0 1 1} \\
(.0006)\end{array}$ & $\begin{array}{l}\mathbf{- 0 . 0 4 2} \\
(.0070)\end{array}$ & $\begin{array}{l}\mathbf{- 0 . 0 3 2} \\
(.0029)\end{array}$ & $\begin{array}{l}\mathbf{- 0 . 0 5 1} \\
(.0064)\end{array}$ & $\begin{array}{l}\mathbf{- 0 . 0 5 5} \\
(.0069)\end{array}$ & $\begin{array}{l}-0.013 \\
(.0072)\end{array}$ \\
\hline INCOME SQ. & - & $\begin{array}{l}\mathbf{0 . 0 0 2} \\
(.0001)\end{array}$ & - & $\begin{array}{l}\mathbf{0 . 0 0 1} \\
(.0003)\end{array}$ & $\begin{array}{l}\mathbf{0 . 0 0 1} \\
(.0001)\end{array}$ & $\begin{array}{l}\mathbf{0 . 0 0 2} \\
(.0003)\end{array}$ & $\begin{array}{l}\mathbf{0 . 0 0 2} \\
(.0003)\end{array}$ & $\begin{array}{l}0.0004 \\
(.0003)\end{array}$ \\
\hline$s_{t-1}$ & - & $\begin{array}{l}- \\
-\end{array}$ & - & $\begin{array}{l}- \\
-\end{array}$ & $\begin{array}{c}\mathbf{0 . 6 1 8} \\
(.0162)\end{array}$ & $\begin{array}{c}\mathbf{0 . 1 1 8} \\
(.0215)\end{array}$ & $\begin{array}{l}\mathbf{0 . 2 5 6} \\
(.0236)\end{array}$ & $\begin{array}{c}\mathbf{0 . 2 9 6} \\
(.0265)\end{array}$ \\
\hline $\begin{array}{c}\text { Wald/F test } \\
\text { Arellano-Bond tes }\end{array}$ & 0.000 & 0.000 & 0.000 & 0.000 & 0.000 & 0.000 & 0.000 & 0.002 \\
\hline 1 & - & - & - & - & - & - & -14.29 & -14.58 \\
\hline 2 & - & - & - & - & - & - & 1.22 & 1.92 \\
\hline 3 & - & - & - & - & - & - & -0.35 & -0.10 \\
\hline Sargan/OIR & - & - & $\begin{array}{l}2.80 \\
(1)\end{array}$ & $\begin{array}{l}0.79 \\
(2)\end{array}$ & - & - & $\begin{array}{c}100.05 \\
(23)\end{array}$ & $\begin{array}{c}407.89 \\
(61)\end{array}$ \\
\hline Obs. & 852,714 & 852,714 & 852,714 & 852,714 & 852,714 & 852,714 & 852,714 & 852,714 \\
\hline
\end{tabular}

Estimation on sample of 55 to 65 year olds. Controls include: Sex, age, education, occupation, geographic location, immigrant/native and marital stat us. Robust standard errors in parentheses. Bold indicates significance at $5 \%$ level. Wald/F test: p-value from test of joint significance of income and income sq. Arellano-Bond tests for first-, second- and third-order serial correlation in the first-differenced residuals. These are asymptotically distributed N( 0,1$)$ under the null of no serial correlation. Sargan test of the over-identifying restrictions is asymptotically chi sq. distributed under the null of instrument validity. Degrees of freedom are reported in parentheses. 
TABLE 3

\begin{tabular}{|c|c|c|c|c|c|c|c|c|}
\hline \multicolumn{9}{|c|}{ Estimation Results: $\leq 65$ YeARS } \\
\hline & OLS & OLS & $\begin{array}{c}\text { IV } \\
2 S L S \\
\end{array}$ & $\begin{array}{c}\text { IV } \\
2 S L S \\
\end{array}$ & OLS & $\begin{array}{r}\text { WITHIN } \\
\text { GROUPS } \\
\end{array}$ & $\begin{array}{c}\text { GMM-SYS } \\
\text { EXOG. }\end{array}$ & $\begin{array}{c}\text { GMM-S YS } \\
\text { ENDOG. }\end{array}$ \\
\hline$s$ & $(1)$ & $(2)$ & (3) & (4) & (5) & (6) & $(7)$ & $(8)$ \\
\hline INCOME & $\begin{array}{l}\mathbf{- 0 . 0 0 7} \\
(.0001)\end{array}$ & $\begin{array}{l}\mathbf{- 0 . 0 2 9} \\
(.0014)\end{array}$ & $\begin{array}{l}\mathbf{- 0 . 0 0 6} \\
(.0002)\end{array}$ & $\begin{array}{l}\mathbf{- 0 . 0 2 6} \\
(.0028)\end{array}$ & $\begin{array}{r}\mathbf{- 0 . 0 2 3} \\
(.0012)\end{array}$ & $\begin{array}{l}\mathbf{- 0 . 0 2 4} \\
(.0017)\end{array}$ & $\begin{array}{l}\mathbf{- 0 . 0 2 6} \\
(.0020)\end{array}$ & $\begin{array}{c}0.003 \\
(.0031)\end{array}$ \\
\hline INCOME SQ. & $\begin{array}{l}- \\
-\end{array}$ & $\begin{array}{l}\mathbf{0 . 0 0 1} \\
(.0001)\end{array}$ & $\begin{array}{l}- \\
-\end{array}$ & $\begin{array}{l}\mathbf{0 . 0 0 1} \\
(.0001)\end{array}$ & $\begin{array}{l}\mathbf{0 . 0 0 1} \\
(.0001)\end{array}$ & $\begin{array}{l}\mathbf{0 . 0 0 1} \\
(.0001)\end{array}$ & $\begin{array}{l}\mathbf{0 . 0 0 1} \\
(.0001)\end{array}$ & $\begin{array}{l}-0.0002 \\
(.0001)\end{array}$ \\
\hline$s_{t-1}$ & - & $\begin{array}{l}- \\
-\end{array}$ & - & $\begin{array}{l}- \\
-\end{array}$ & $\begin{array}{c}\mathbf{0 . 5 3 1} \\
(.0100)\end{array}$ & $\begin{array}{c}\mathbf{0 . 1 2 4} \\
(.0102)\end{array}$ & $\begin{array}{c}\mathbf{0 . 2 2 1} \\
(.0109)\end{array}$ & $\begin{array}{c}\mathbf{0 . 2 4 4} \\
(.0115)\end{array}$ \\
\hline $\begin{array}{c}\text { Wald/F test } \\
\text { Arellano-Bond test }\end{array}$ & 0.000 & 0.000 & 0.000 & 0.000 & 0.000 & 0.000 & 0.000 & 0.000 \\
\hline 1 & - & - & - & - & - & - & -25.99 & -26.09 \\
\hline 2 & - & - & - & - & - & - & 4.75 & 5.59 \\
\hline 3 & - & - & - & - & - & - & -1.54 & -1.08 \\
\hline Sargan/OIR & - & - & $\begin{array}{c}13.00 \\
(1)\end{array}$ & $\begin{array}{c}7.41 \\
(2)\end{array}$ & - & - & $\begin{array}{c}282.46 \\
(23)\end{array}$ & $\begin{array}{c}1217.51 \\
(61)\end{array}$ \\
\hline Obs. & $3,987,166$ & $3,987,166$ & $3,987,166$ & $3,987,166$ & $3,987,166$ & $3,987,166$ & $3,987,166$ & $3,987,166$ \\
\hline
\end{tabular}

Estimation on sample of individuals aged 65 and below Controls include: Sex, age, education, occupation, geographic location, immigrant/native and marital status. Robust standard errors in parentheses. Bold indicates significance at 5\% level. Wald/F test: p-value from test of joint significance of income and income sq. Arellano-Bond tests for first-, second- and third-order serial correlation in the first-differenced residuals. These are asymptotically distributed $\mathrm{N}(0,1)$ under the null of no serial correlation. Sargan test of the over-identifying restrictions is asymptotically chi sq. distributed under the null of instrument validity. Degrees of freedom are reported in parentheses.

TABLE 4

\begin{tabular}{|c|c|c|c|c|}
\hline \multicolumn{5}{|c|}{ OLs vs. TOBIT ESTIMATION } \\
\hline & OLS & TOBIT & OLS & TOBIT \\
\hline$s$ & (1) & (2) & (3) & (4) \\
\hline \multirow[t]{2}{*}{ INCOME } & -0.0113 & -0.0121 & -0.0535 & -0.0527 \\
\hline & $(.0002)$ & $(.0003)$ & $(.0036)$ & $(.0008)$ \\
\hline \multirow[t]{2}{*}{ INCOME SQ. } & - & - & 0.0018 & 0.0018 \\
\hline & - & - & $(.0001)$ & $(.00003)$ \\
\hline Censored obs. & 193,716 & 193,716 & 193,716 & 193,716 \\
\hline \multirow{2}{*}{$\begin{array}{c}\text { Uncensored obs. } \\
\text { Total obs. }\end{array}$} & 658,998 & 658,998 & 658,998 & 658,998 \\
\hline & 852,714 & 852,714 & 852,714 & 852,714 \\
\hline
\end{tabular}

Estimation on sample of 55 to 65 year olds. Controls include: Sex, age, education, occupation, geographic location, immigrant/native and marital status. Robust standard errors in parentheses. Bold indicates significance at $5 \%$ level. 
TABLE 5

\begin{tabular}{|c|c|c|c|c|c|c|c|c|}
\hline \multicolumn{9}{|c|}{ Estimation Results: 55-65 Years HouseHold InCOME } \\
\hline & OLS & OLS & $\begin{array}{c}\text { IV } \\
2 S L S \\
\end{array}$ & $\begin{array}{c}\text { IV } \\
2 S L S \\
\end{array}$ & OLS & $\begin{array}{r}\text { WITHIN } \\
\text { GROUPS } \\
\end{array}$ & $\begin{array}{c}\text { GMM-SYS } \\
\text { EXOG. }\end{array}$ & $\begin{array}{c}\text { GMM-S YS } \\
\text { ENDOG. }\end{array}$ \\
\hline$s$ & (1) & (2) & (3) & (4) & (5) & (6) & (7) & $(8)$ \\
\hline INCOME & $\begin{array}{r}\mathbf{- 0 . 0 0 4} \\
(.0001)\end{array}$ & $\begin{array}{r}\mathbf{- 0 . 0 3 3} \\
(.0056)\end{array}$ & $\begin{array}{r}-\mathbf{- 0 . 0 0 3} \\
(.0003)\end{array}$ & $\begin{array}{r}\mathbf{- 0 . 0 3 4} \\
(.0111)\end{array}$ & $\begin{array}{r}\mathbf{- 0 . 0 2 6} \\
(.0052)\end{array}$ & $\begin{array}{r}\mathbf{- 0 . 0 4 0} \\
(.0100)\end{array}$ & $\begin{array}{r}\mathbf{- 0 . 0 4 3} \\
(.0104)\end{array}$ & $\begin{array}{l}-0.007 \\
(.0097)\end{array}$ \\
\hline INCOME SQ. & - & $\begin{array}{l}\mathbf{0 . 0 0 1} \\
(.0002)\end{array}$ & - & $\begin{array}{c}\mathbf{0 . 0 0 1} \\
(.0004)\end{array}$ & $\begin{array}{c}\mathbf{0 . 0 0 1} \\
(.0002)\end{array}$ & $\begin{array}{c}\mathbf{0 . 0 0 1} \\
(.0004)\end{array}$ & $\begin{array}{l}\mathbf{0 . 0 0 1} \\
(.0004)\end{array}$ & $\begin{array}{l}0.0003 \\
(.0004)\end{array}$ \\
\hline$s_{t-1}$ & - & $\begin{array}{l}- \\
-\end{array}$ & - & - & $\begin{array}{l}\mathbf{0 . 6 3 8} \\
(.0343)\end{array}$ & $\begin{array}{l}\mathbf{0 . 1 1 0} \\
(.0431)\end{array}$ & $\begin{array}{l}\mathbf{0 . 2 5 6} \\
(.0482)\end{array}$ & $\begin{array}{l}\mathbf{0 . 2 7 8} \\
(.0504)\end{array}$ \\
\hline $\begin{array}{c}\text { Wald/F test } \\
\text { Arellano-Bond test }\end{array}$ & 0.000 & 0.000 & 0.000 & 0.000 & 0.000 & 0.000 & 0.000 & 0.757 \\
\hline 1 & - & - & - & - & - & - & -7.68 & -7.52 \\
\hline 2 & - & - & - & - & - & - & 2.67 & 3.32 \\
\hline 3 & - & - & - & - & - & - & 0.51 & 0.06 \\
\hline Sargan/OIR & - & - & $\begin{array}{l}4.05 \\
(1)\end{array}$ & $\begin{array}{l}3.73 \\
(2)\end{array}$ & - & - & $\begin{array}{c}381.46 \\
(23)\end{array}$ & $\begin{array}{c}1100.37 \\
(61)\end{array}$ \\
\hline Obs. & 852,714 & 852,714 & 852,714 & 852,714 & 852,714 & 852,714 & 852,714 & 852,714 \\
\hline
\end{tabular}

Estimation on sample of 55 to 65 year olds using household income. Controls include: Sex, age, education, occupation, geographic location,

immigrant/native and marital status. Robust standard errors in parentheses. Bold indicates significance at 5\% level. Wald/F test: p-value from test of joint significance of income and income sq. Arellano-Bond tests for first-, second- and third-order serial correlation in the first-differenced residuals. These are asymptotically distributed $\mathrm{N}(0,1)$ under the null of no serial correlation. Sargan test of the over-identifying restrictions is asymptotically chi sq. distributed under the null of instrument validity. Degrees of freedom are reported in parentheses. 
TABLE 6

\begin{tabular}{|c|c|c|c|c|c|c|c|c|}
\hline \multicolumn{9}{|c|}{ Estimation RESUlts: 55-65 YeARS - Women } \\
\hline & OLS & OLS & $\begin{array}{c}\text { IV } \\
2 S L S \\
\end{array}$ & $\begin{array}{c}\text { IV } \\
2 S L S \\
\end{array}$ & OLS & $\begin{array}{r}\text { WITHIN } \\
\text { GROUPS }\end{array}$ & $\begin{array}{c}\text { GMM-SYS } \\
\text { EXOG. }\end{array}$ & $\begin{array}{c}\text { GMM-S YS } \\
\text { ENDOG. }\end{array}$ \\
\hline$s$ & (1) & (2) & (3) & (4) & (5) & (6) & (7) & $(8)$ \\
\hline INCOME & $\begin{array}{l}\mathbf{- 0 . 0 1 6} \\
(.0004)\end{array}$ & $\begin{array}{l}\mathbf{- 0 . 0 4 6} \\
(.0046)\end{array}$ & $\begin{array}{l}\mathbf{- 0 . 0 1 5} \\
(.0010)\end{array}$ & $\begin{array}{r}\mathbf{- 0 . 0 3 3} \\
(.0092)\end{array}$ & $\begin{array}{r}\mathbf{- 0 . 0 2 8} \\
(.0036)\end{array}$ & $\begin{array}{l}\mathbf{- 0 . 0 4 5} \\
(.0079)\end{array}$ & $\begin{array}{l}\mathbf{- 0 . 0 5 1} \\
(.0084)\end{array}$ & $\begin{array}{l}-0.015 \\
(.0093)\end{array}$ \\
\hline INCOME SQ. & - & $\begin{array}{l}\mathbf{0 . 0 0 1} \\
(.0002)\end{array}$ & $\begin{array}{l}- \\
-\end{array}$ & $\begin{array}{l}\mathbf{0 . 0 0 1} \\
(.0004)\end{array}$ & $\begin{array}{l}\mathbf{0 . 0 0 1} \\
(.0002)\end{array}$ & $\begin{array}{l}\mathbf{0 . 0 0 1} \\
(.0003)\end{array}$ & $\begin{array}{l}\mathbf{0 . 0 0 1} \\
(.0003)\end{array}$ & $\begin{array}{l}0.0003 \\
(.0004)\end{array}$ \\
\hline$s_{t-1}$ & - & - & $\begin{array}{l}- \\
-\end{array}$ & - & $\begin{array}{l}\mathbf{0 . 6 2 0} \\
(.0181)\end{array}$ & $\begin{array}{l}\mathbf{0 . 1 2 4} \\
(.0242)\end{array}$ & $\begin{array}{l}\mathbf{0 . 2 5 6} \\
(.0275)\end{array}$ & $\begin{array}{l}\mathbf{0 . 3 0 1} \\
(.0311)\end{array}$ \\
\hline $\begin{array}{c}\text { Wald/F test } \\
\text { Arellano-Bond test }\end{array}$ & 0.000 & 0.000 & 0.000 & 0.000 & 0.000 & 0.000 & 0.000 & 0.000 \\
\hline 1 & - & - & - & - & - & - & -12.59 & -12.80 \\
\hline 2 & - & - & - & - & - & - & 0.49 & 1.05 \\
\hline 3 & - & - & - & - & - & - & 0.14 & 0.42 \\
\hline Sargan/OIR & - & - & $\begin{array}{l}4.94 \\
(1)\end{array}$ & $\begin{array}{l}3.47 \\
(2)\end{array}$ & - & - & $\begin{array}{c}80.32 \\
(24)\end{array}$ & $\begin{array}{c}250.49 \\
(62)\end{array}$ \\
\hline Obs. & 427,814 & 427,814 & 427,814 & 427,814 & 427,814 & 427,814 & 427,814 & 427,814 \\
\hline
\end{tabular}

Estimation on sample of women, 55 to 65 year olds. Controls include: Age, education, occupation, geographic location, immigrant/native and marital status. Robust standard errors in parentheses. Bold indicates significance at $5 \%$ level. Wald/F test: p-value from test of joint significance of income and income sq. Arellano-Bond tests for first-, second- and third-order serial correlation in the first-differenced residuals. These are asymptotically distributed $\mathrm{N}(0,1)$ under the null of no serial correlation. Sargan test of the over-identifying restrictions is asymptotically chi sq. distributed under the null of instrument validity. Degrees of freedom are reported in parentheses. 
TABLE 7

\begin{tabular}{|c|c|c|c|c|c|c|c|c|}
\hline \multicolumn{9}{|c|}{ Estimation Results: 55-65 Years - Men } \\
\hline & OLS & OLS & $\begin{array}{c}\text { IV } \\
2 S L S \\
\end{array}$ & $\begin{array}{c}\text { IV } \\
2 S L S \\
\end{array}$ & OLS & $\begin{array}{r}\text { WITHIN } \\
\text { GROUPS }\end{array}$ & $\begin{array}{c}\text { GMM-SYS } \\
\text { EXOG. }\end{array}$ & $\begin{array}{c}\text { GMM-S YS } \\
\text { ENDOG. }\end{array}$ \\
\hline$s$ & $(1)$ & (2) & (3) & (4) & (5) & (6) & (7) & (8) \\
\hline INCOME & $\begin{array}{l}\mathbf{- 0 . 0 0 6} \\
(.0002)\end{array}$ & $\begin{array}{l}\mathbf{- 0 . 0 3 9} \\
(.0066)\end{array}$ & $\begin{array}{l}\mathbf{- 0 . 0 0 5} \\
(.0005)\end{array}$ & $\begin{array}{r}\mathbf{- 0 . 0 2 9} \\
(.0105)\end{array}$ & $\begin{array}{r}\mathbf{- 0 . 0 3 2} \\
(.0060)\end{array}$ & $\begin{array}{l}\mathbf{- 0 . 0 4 5} \\
(.0112)\end{array}$ & $\begin{array}{l}\mathbf{- 0 . 0 5 0} \\
(.0121)\end{array}$ & $\begin{array}{l}-0.003 \\
(.0102)\end{array}$ \\
\hline INCOME SQ. & - & $\begin{array}{l}\mathbf{0 . 0 0 1} \\
(.0003)\end{array}$ & $\begin{array}{l}- \\
-\end{array}$ & $\begin{array}{l}\mathbf{0 . 0 0 1} \\
(.0004)\end{array}$ & $\begin{array}{l}\mathbf{0 . 0 0 1} \\
(.0002)\end{array}$ & $\begin{array}{l}\mathbf{0 . 0 0 2} \\
(.0004)\end{array}$ & $\begin{array}{l}\mathbf{0 . 0 0 2} \\
(.0005)\end{array}$ & $\begin{array}{l}0.0001 \\
(.0004)\end{array}$ \\
\hline$s_{t-1}$ & - & - & $\begin{array}{l}- \\
-\end{array}$ & - & $\begin{array}{l}\mathbf{0 . 5 8 9} \\
(.0356)\end{array}$ & $\begin{array}{c}0.074 \\
(.0432)\end{array}$ & $\begin{array}{l}\mathbf{0 . 2 2 5} \\
(.0393)\end{array}$ & $\begin{array}{l}\mathbf{0 . 2 5 6} \\
(.0426)\end{array}$ \\
\hline $\begin{array}{c}\text { Wald/F test } \\
\text { Arellano-Bond test }\end{array}$ & 0.000 & 0.000 & 0.000 & 0.000 & 0.000 & 0.000 & 0.000 & 0.455 \\
\hline 1 & - & - & - & - & - & - & -7.22 & -7.04 \\
\hline 2 & - & - & - & - & - & - & 2.26 & 2.65 \\
\hline 3 & - & - & - & - & - & - & -1.04 & -1.00 \\
\hline Sargan/OIR & - & - & $\begin{array}{c}0.78 \\
(1)\end{array}$ & $\begin{array}{l}0.01 \\
(2)\end{array}$ & - & - & $\begin{array}{c}179.97 \\
(24)\end{array}$ & $\begin{array}{c}650.50 \\
(62)\end{array}$ \\
\hline Obs. & 424,900 & 424,900 & 424,900 & 424,900 & 424,900 & 424,900 & 424,900 & 424,900 \\
\hline
\end{tabular}

Estimation on sample of men, 55 to 65 year olds. Controls include: Age, education, occupation, geographic location, immigrant/native and marital status. Robust standard errors in parentheses. Bold indicates significance at $5 \%$ level. Wald/F test: p-value from test of joint significance of income and income sq. Arellano-Bond tests for first-, second- and third-order serial correlation in the first-differenced residuals. These are asymptotically distributed $\mathrm{N}(0,1)$ under the null of no serial correlation. Sargan test of the over-identifying restrictions is asymptotically chi sq. distributed under the null of instrument validity. Degrees of freedom are reported in parentheses. 
Figures to be inserted in the text

FIGURE 1

KERNEL REGRESSION OF EXPENDITURE SHARE ON AGE

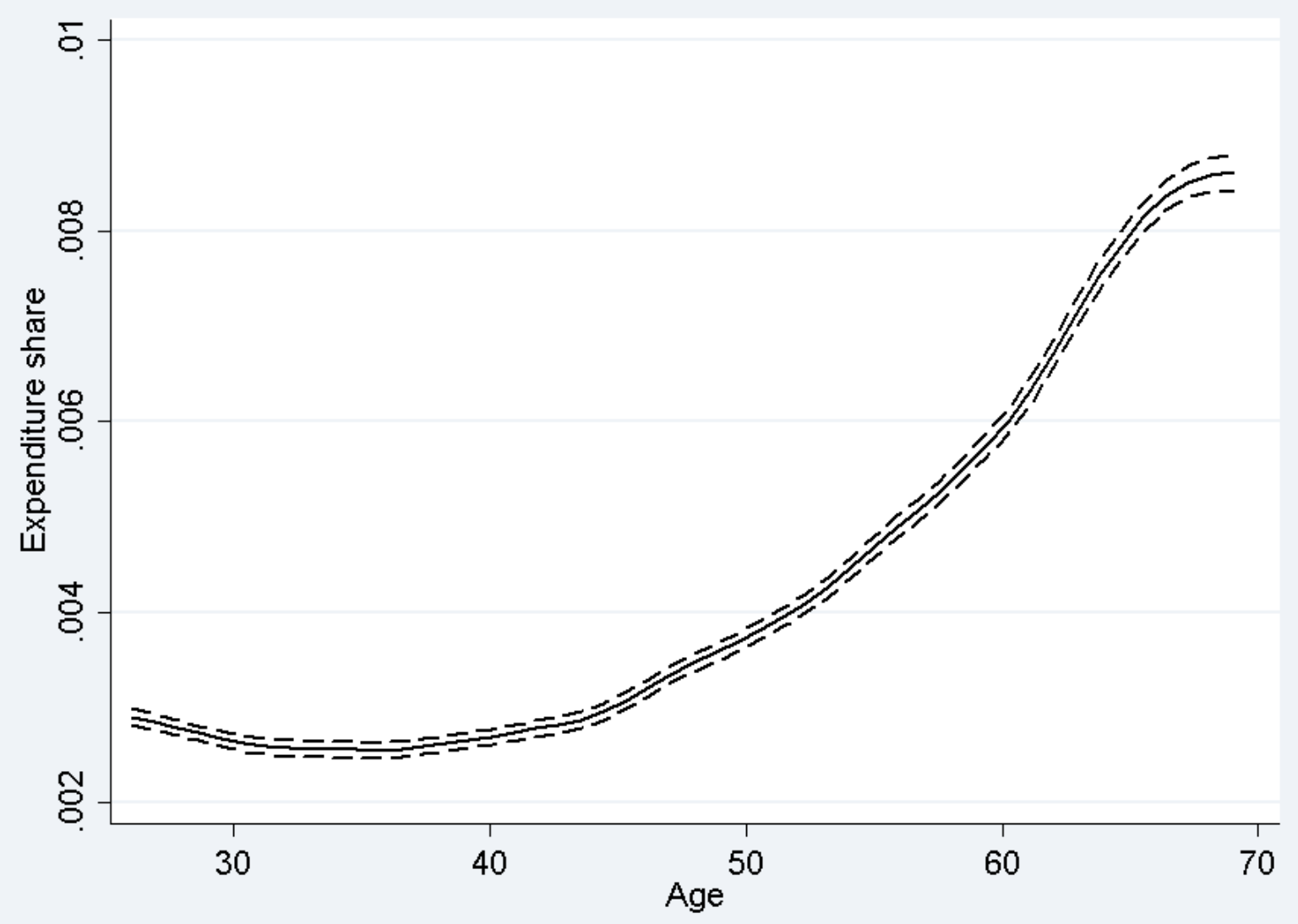

Local polynomial regression of age on the expenditure share. Cross-section, year 2003. Dashed lines are 95\% confidence interval. 
FIGURE 2

KERNEL REGRESSION OF LOG INCOME ON AGE

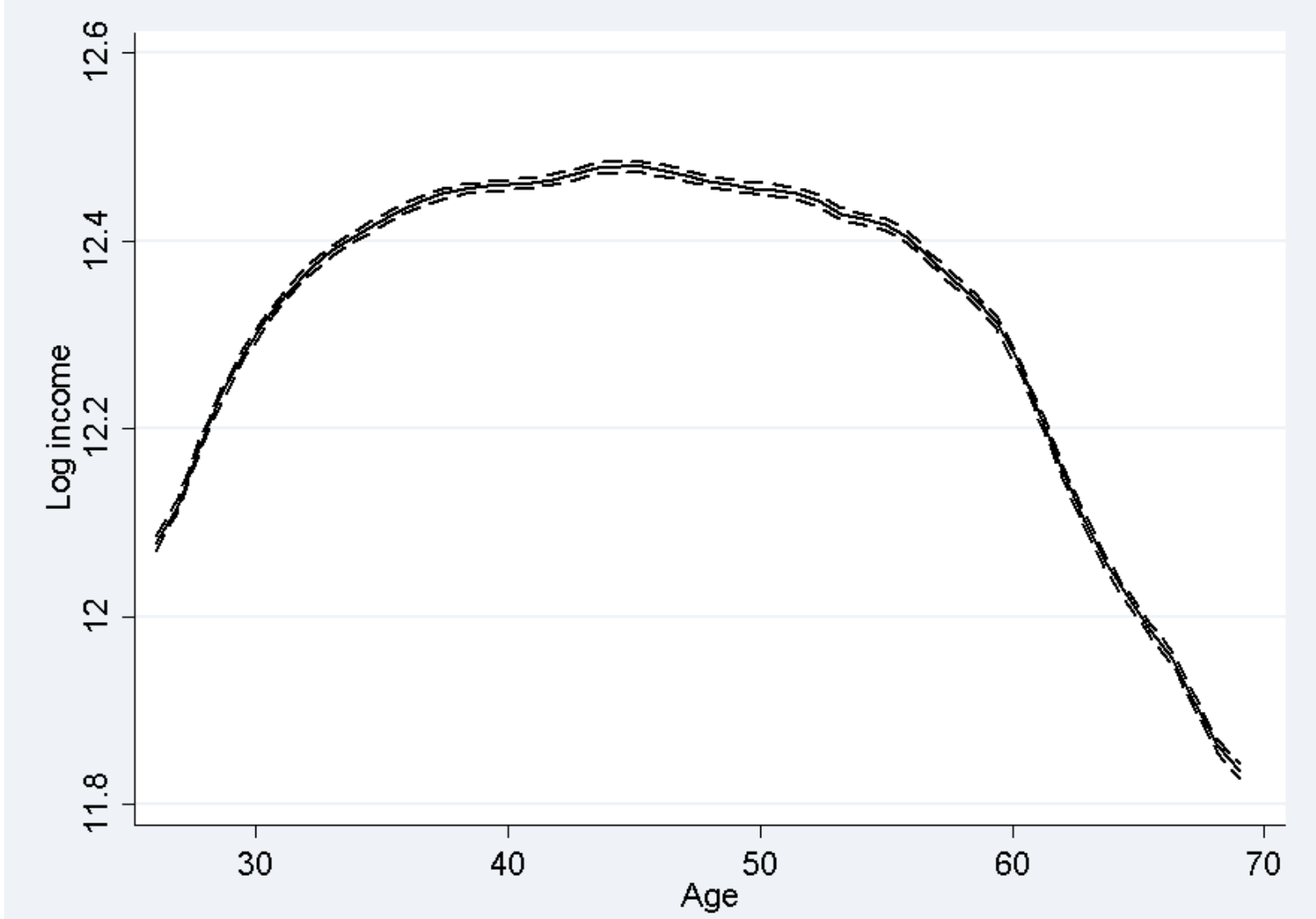

Local polynomial regression of age on the log income. Cross-section, year 2003. Dashed lines are 95\% confidence interval. 
FIGURE 3

KERNEL REGRESSION OF EXPENDITURE SHARE ON LOG INCOME

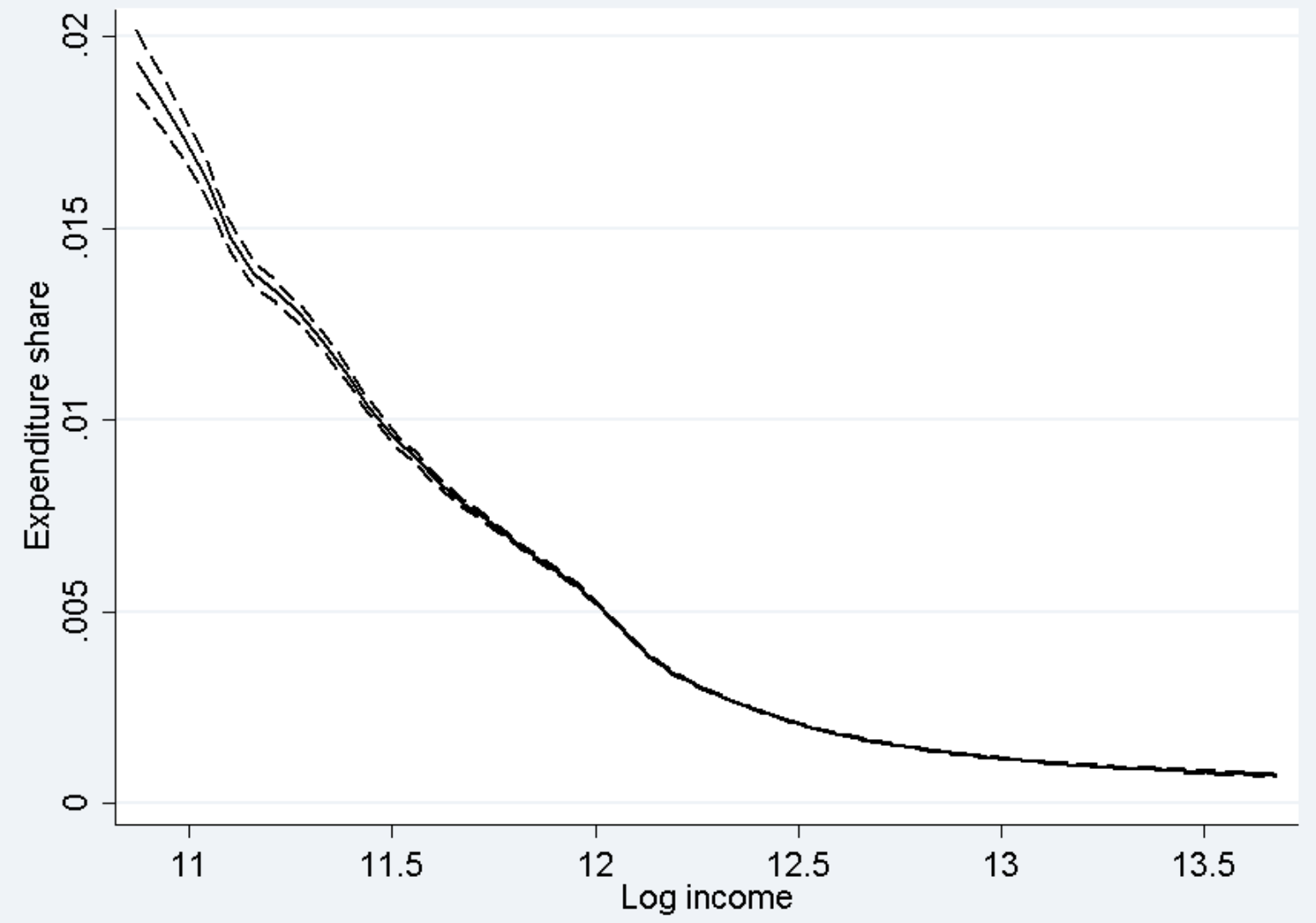

Local polynomial regression of log income on the prescription drug expenditure share. Cross-section, year 2003. Dashed lines are $95 \%$ confidence interval. 
FIGURE 4

KERNEL REGRESSION OF EXPENDITURE SHARE ON LOG INCOME BY AGE GROUP

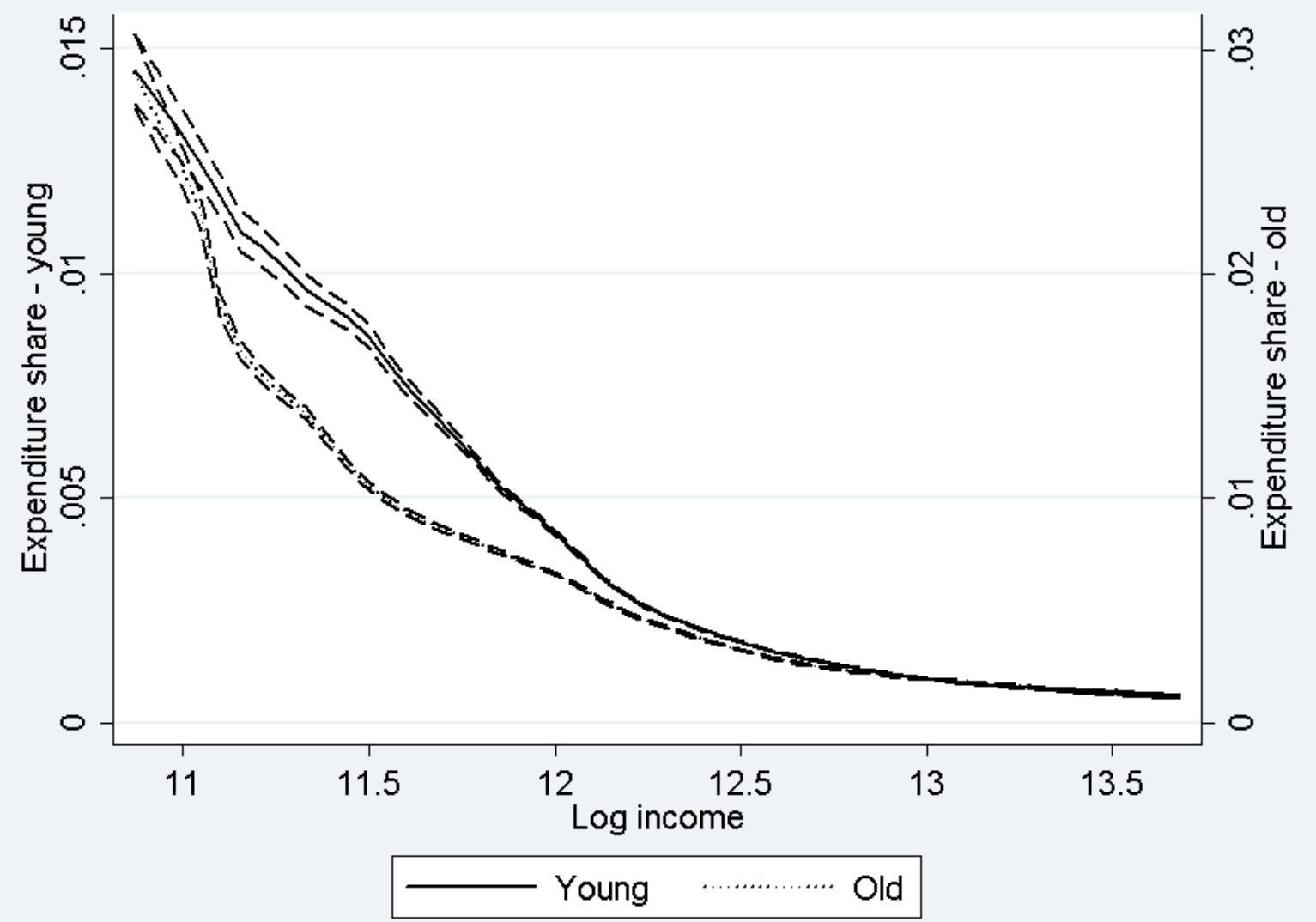

Local polynomial regression of log income on the prescription drug expenditure share by age. Young are individuals below the age of 55 and old are individuals aged 55 to 70 . Cross-section, year 2003. Dashed lines are 95\% confidence interval. 
FIGURE 5

EXPENDITURE SHARE CHANGES FROM AGE 66 TO 68 For Full SAMPLE

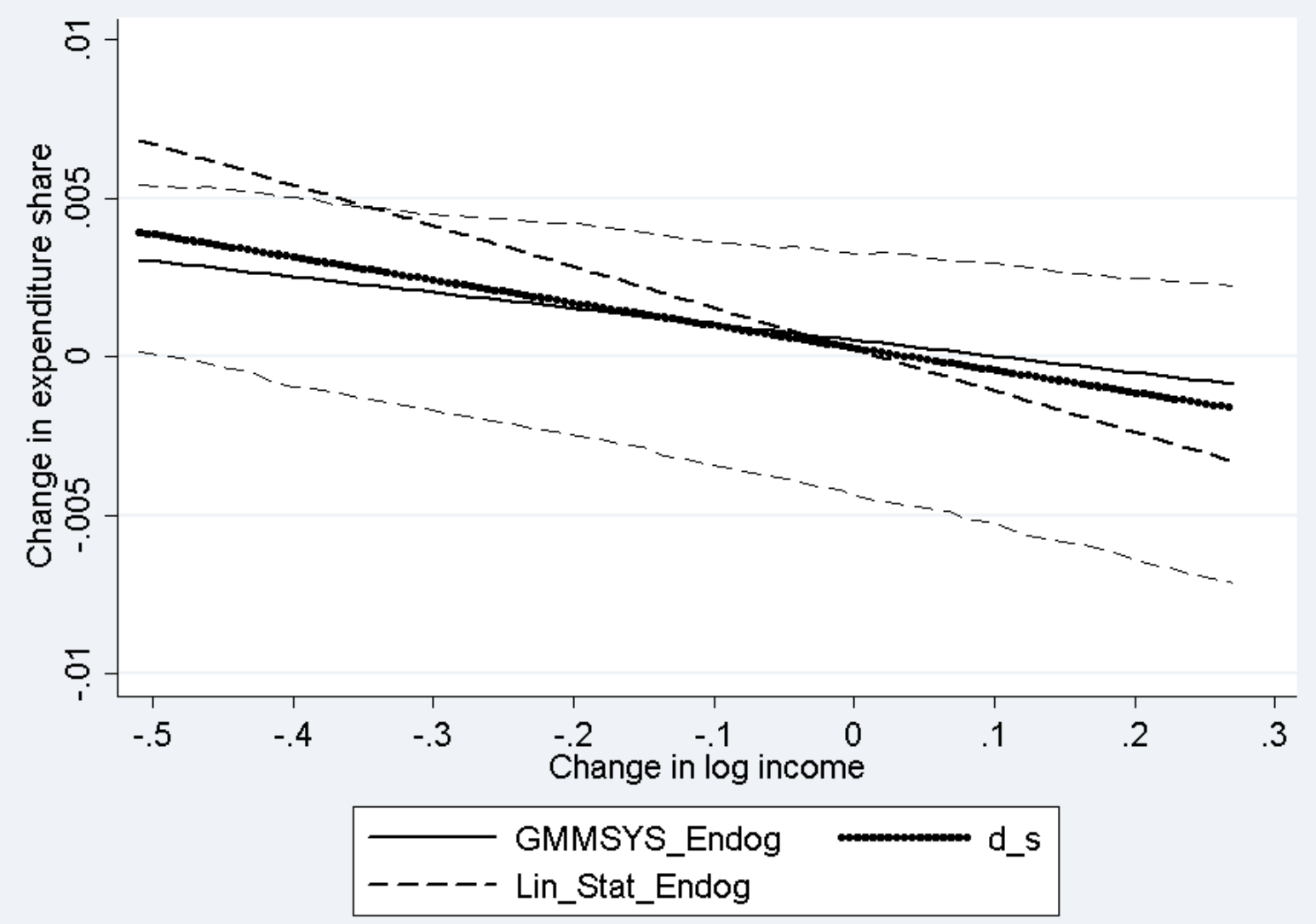

Plot of the predictions from the GMM-SYS estimator and the linear static model with income treated as endogenous. The dotted line is the actual expenditure share changes. The graph only depicts $80 \%$ of the distribution of income changes. $10 \%$ in the top/bottom has been left out. 95\% confidence bands for GMM-SYS predictions are reported. These are bootstrapped using 1,000 replications. 
FIGURE 6

EXPENDITURE SHARE CHANGES FROM AGE 66 TO 68 FOR SUB SAMPLE OF WAGE EARNERS AT 66

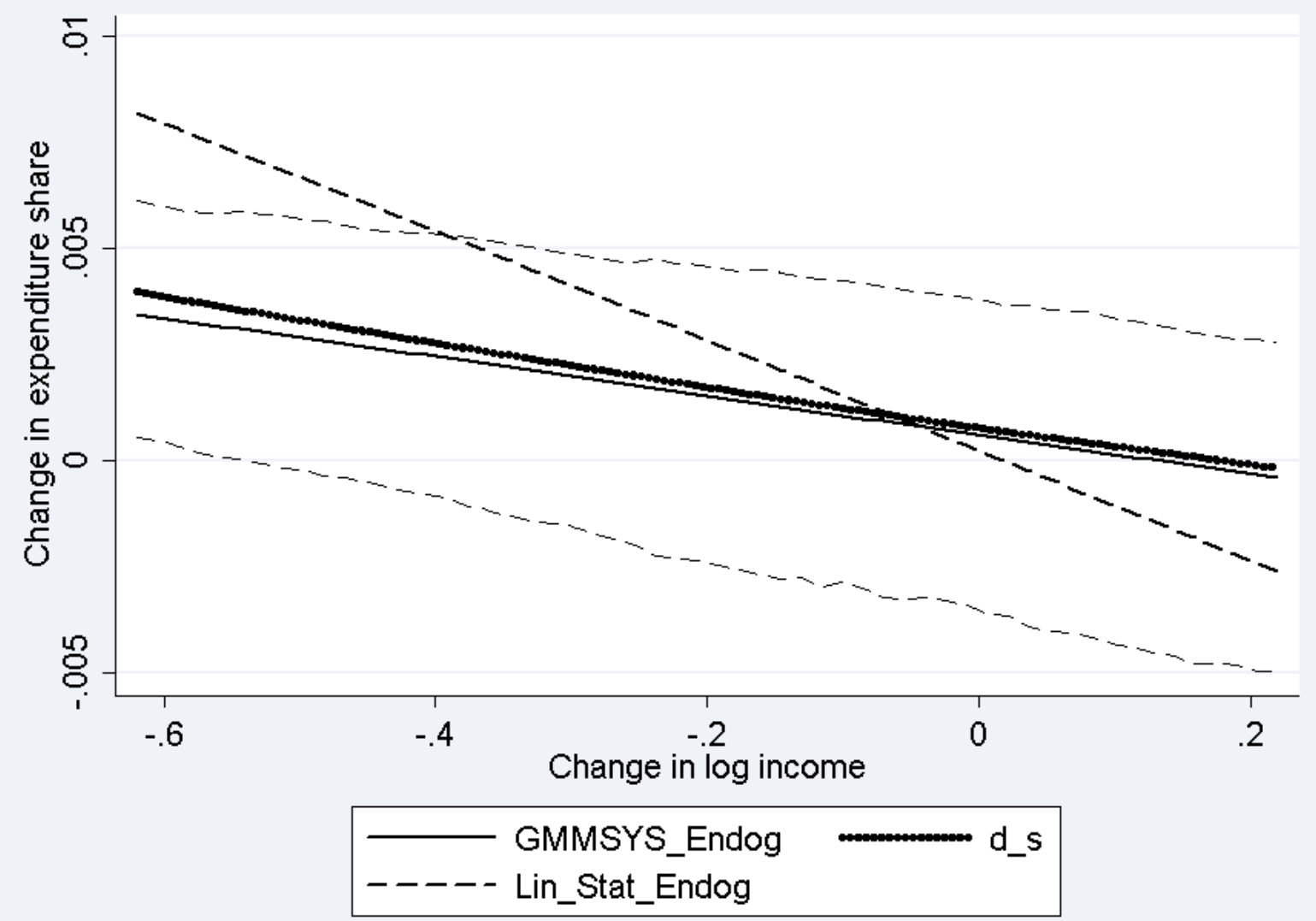

Plot of the predictions from the GMM-SYS estimator and the linear static model with income treated as endogenous. The dotted line is the actual expenditure share changes. The graph only depicts $80 \%$ of the distribution of income changes. $10 \%$ in the top/bottom has been left out. 95\% confidence bands for GMM-SYS predictions are reported. These are bootstrapped using 1,000 replications. 


\section{Economics Working Paper}

2009-17: Hristos Doucouliagos and Martin Paldam: Development Aid and Growth: An association converging to zero

2009-18: Christian Bjørnskov and Martin Paldam: The spirits of capitalism and socialism. A cross-country study of ideology

2010-1: $\quad$ Laurent Callot and Martin Paldam: Natural funnel asymmetries. A simulation analysis of the three basic tools of meta analysis

2010-2: $\quad$ Allan Sørensen: Welfare Effects of Trade Liberalization with Intra-industry Reallocations: The Importance of Preferences and Market Failures

2010-3: $\quad$ Marianne Simonsen, Lars Skipper and Niels Skipper: Price Sensitivity of Demand for Prescription Drugs: Exploiting a Regression Kink Design

2010-4: $\quad$ Torben M. Andersen and Allan Sørensen: Product market integration, rents and wage inequality

2010-5: John Kennes and Daniel le Maire: Coordination Frictions and Job Heterogeneity: A Discrete Time Analysis

2010-6: $\quad$ Philipp J.H. Schröder and Allan Sørensen: The Theoretical Equivalent of Empirically Measurable Exporter Productivity when Firms are Heterogeneous

2010-7: $\quad$ Nabanita Datta Gupta and Marianne Simonsen: Effects of Universal Child Care Participation on Pre-teen Skills and Risky Behaviors

2010-8: $\quad$ Olaf Posch and Timo Trimborn: Numerical solution of continuous-time DSGE models under Poisson uncertainty

2010-9: Torben M. Andersen and Allan Sørensen: Globalization, tax distortions and public sector retrenchment

2010-10: $\quad$ Philipp J.H. Schröder and Allan Sørensen: Ad valorem versus unit taxes: Monopolistic competition, heterogeneous firms, and intra-industry reallocations

2010-11: Søren Leth-Petersen and Niels Skipper: Income and the use of prescription drugs for near retirement individuals 